\title{
AS TUTELAS PROVISÓRIAS COMO MECANISMO DE CELERIDADE DA PRESTAÇÃO JURISDICIONAL NO CÓDIGO DE PROCESSO CIVIL DE 2015
}

\section{PROVISIONAL PROTECTION AS A CELLERITY MECHANISM FOR LEGAL PROVISION IN THE 2015 CIVIL PROCEDURE CODE}

\section{Sâmara Camisão Pechir}

Pós Graduada em Direito Penal e Direito Processual Penal pelo Instituto Damásio de Direito. Atua como advogada há 03 anos nas áreas de Direito Civil, Direito Penal, Direito Trabalhista e Previdenciário.

\section{Luana Pacheco Guimarães}

Pós Graduada em Direito Público pela Universidade Anhanguera de São Paulo nas áreas de Direito Constitucional, Administrativo, Tributário e Previdenciário, atua como advogada há 07 anos nas áreas de direito civil , administrativo e previdenciário, exerce atividade de Magistério junto a Faculdade Presidente Antônio Carlos de Teófilo Otoni/MG.

\section{Resumo}

O presente trabalho acadêmico tem como objetivo analisar as tutelas provisórias dentro da Lei no 13.105, o Código de Processo Civil de 2015, visando e abordando a real eficácia deste instituto processual e a sua colaboração e eficiência no tangente a prestação da tutela jurisdicional. Trata-se de uma pesquisa documental e bibliográfica utilizando-se da análise minuciosa da legislação, entendimento jurisprudencial e dos ensinamentos doutrinários, levando em consideração as contribuições de autores como ALVIM (2016), BUENO (2016), CAPPELLETTI (1988), NEVES (2016) e TALAMIN (2018). O tema em questão possui relevância, haja vista que mesmo com a previsão legal de tais mecanismos processuais, o sistema processual brasileiro ainda é moroso e ineficaz em boa parte de suas facetas. Desta forma, é de suma relevância o estudo do tema, em face da necessidade de meios que contribuam para a celeridade e efetividade da prestação da tutela jurisdicional, garantindo a toda sociedade as garantias constitucionais, dentre elas a do acesso a duração razoável do processo.

Palavras-chave: Tutelas provisórias. Celeridade Processual. Duração razoável do Processo. Prestação da tutela jurisdicional.

\section{Abstract}


This academic work aims to analyze the provisional tutelage within the Law No. 13.105, the Civil Procedure Code of 2015, aiming and addressing the real effectiveness of this procedural institute and its collaboration and efficiency in the provision of judicial protection. It is a documentary and bibliographical research using the thorough analysis of the legislation, jurisprudential understanding and doctrinal teachings, taking into consideration the contributions of authors such as ALVIM (2016), BUENO (2016), CAPPELLETTI (1988), NEVES (2016) and TALAMIN (2018). The issue in question is extremely relevant, given that even with the legal provision of such procedural mechanisms, the Brazilian procedural system is still slow and ineffective in most of its facets. Thus, the study of the subject is extremely relevant, given the need for means that contribute to the speed and effectiveness of the provision of judicial protection, guaranteeing to all society the constitutional guarantees, including the access to reasonable duration of the process.

Keywords: Provisional tutelage. Procedural Speed. Reasonable Duration of the Process. Provision of judicial protection.

\section{Introdução}

O presente estudo aborda sobre as Tutelas provisórias dentro do ordenamento jurídico brasileiro, que adveio graças a lei 13.105 de 2015, e tem como função atribuir celeridade aos processos jurídicos que tramitam na justiça brasileira, garantido à sociedade a efetivação da tutela jurisdicional, nos termos da Constituição Federal, que garante a todos, a razoável duração do processo e a celeridade da sua tramitação no âmbito judicial e administrativo.

Assim sendo, esse estudo analisa de maneira sucinta a constitucionalidade do instituto da tutela provisória, abordando as garantias constitucionais em relação a efetividade da prestação da tutela jurisdicional e a duração razoável do processo e do acesso à ordem jurídica.

Os principais questionamentos que nortearam este trabalho acadêmico são:

- A utilização das tutelas provisórias contribuem para que haja a celeridade processual dentro do ordenamento jurídico?

- Os procedimentos judiciais conseguem satisfazer com eficiência a prestação da tutela jurisdicional em tempo hábil e de forma eficaz?

O estudo da tutela provisória, de urgência e evidência, que fora realizado no presente trabalho, teve como principal escopo a demonstração da real efetividade destes institutos no processo judicial. E para se atingir as metas propostas, utilizouse da analise da legislação brasileira e doutrinas jurídicas, encontrando-se 
fundamentado por idéias e conceituações de autores como: ALVIM (2016), BUENO (2016), NEVES (2016) e TALAMIN (2016), que trazem uma conceituação e algumas definições acerca do instituto das tutelas provisórias. E ainda CAPPELLETTI (1988) que demonstra alguns dos problemas no sistema judiciário que podem ser combatido pelas tutelas provisórias.

\title{
2 Desenvolvimento
}

As tutelas provisórias foram trazidas ao nosso ordenamento jurídico por intermédio da Lei. № 13.105 de 2015, e podem ser definidas como um meio ao qual o poder judiciário concede, por meio de uma decisão provisória, a prestação tutela jurisdicional, desde que atendidos os requisitos previstos por lei.

O doutrinador Cássio Scarpinella Bueno (2016, p. 247) conceitua a tutela provisória da seguinte maneira:

\begin{abstract}
A tutela provisória, tal qual disciplinada pelo CPC de 2015, como o conjunto de técnicas que permite ao magistrado, na presença de determinados pressupostos, que gravitam em torno da presença da "urgência" ou da "evidência", prestar tutela jurisdicional, antecedente ou incidentalmente, com base em decisão instável (por isso, provisória) apta a assegurar e/ou satisfazer, desde logo, a pretensão do autor.
\end{abstract}

As tutelas provisórias se dividem em tutela provisória de urgência e de evidência e estão elencadas no novo CPC a partir de seu art. 294.

As tutelas provisórias de urgência poderão ser utilizadas quando a parte demonstrar elementos que indiquem a probabilidade do direito ou caso seja demonstrado o perigo da morosidade da prestação da tutela jurisdicional para o resultado útil do processo, nos termos do art. 300 do CPC, conforme demonstra-se a seguir:

Art. 300. A tutela de urgência será concedida quando houver elementos que evidenciem a probabilidade do direito e o perigo de dano ou o risco ao resultado útil do processo. (BRASIL, 2015)

Para fins de conceituação, ressalta-se que as tutelas de urgência se subdividem em tutela provisória de urgência cautelar e a antecipada, sendo que, ambas podem ser deferidas em caráter incidental ou antecedente, conforme entendimento de Daniel Amorim Assumpção Neves (2016, p. 809), entende que 
"nos termos do art. 294, parágrafo único, do Novo CPC, a tutela provisória de urgência, cautelar ou antecipada, pode ser concedida em caráter antecedente ou incidental”. O doutrinador Daniel Amorim Assumpção Neves (2016, p. 966) vai além e diferencia as tutelas de caráter antecedente ou cautelar da seguinte maneira:

A natureza jurídica, entretanto, não pode ser definida pela vontade do legislador, restando inalterada a distinção entre a tutela cautelar como garantidora do resultado útil e eficaz do processo e a tutela antecipada como satisfativa do direito da parte no plano fático.

Deste modo, a tutela de urgência tem a finalidade de garantir a efetividade da prestação do direito material ou processual suscitado pela parte, tendo natureza satisfativa, no caso da tutela de urgência antecipada ou ainda natureza conservatória no caso da tutela de urgência cautelar.

Por outro lado, as tutelas da evidência, previstas no art. 311 do CPC, prescindem do perigo da demora ao resultado do processo e podem ser utilizadas quando restar demonstrado o abuso do direito de defesa ou interesse único e exclusivo de protelar da parte contrária, conforme ensina Eduardo Talamini (2016).

Neste sentido, o doutrinador Arruda Alvim (2016, p. 194) entende que a tutela de evidência tem a função de conceder proteção ao direito da parte, conforme se demonstra:

\footnotetext{
A tutela da evidência quer proteger o requerente que tem a seu favor uma flagrância tão grande do direito que justifica, como dito nos tópicos anteriores, a redistribuição do ônus de suportar o tempo do processo, mesmo sem a situação de urgência.
}

Além das hipóteses mostradas acima, permite-se o uso da tutela de evidência quando as alegações dos fatos trazidos pelo autor puderem ser comprovadas por intermédio de provas documentai, desde que haja tese firmada em demandas repetitivas ou em súmula vinculante. O art. 311 do CPC traz outras possibilidades, conforme demonstra-se a seguir:

Art. 311. A tutela da evidência será concedida, independentemente da demonstração de perigo de dano ou de risco ao resultado útil do processo, quando:

I - Ficar caracterizado o abuso do direito de defesa ou o manifesto propósito protelatório da parte; 
II - As alegações de fato puderem ser comprovadas apenas documentalmente e houver tese firmada em julgamento de casos repetitivos ou em súmula vinculante;

III - se tratar de pedido reipersecutório fundado em prova documental adequada do contrato de depósito, caso em que será decretada a ordem de entrega do objeto custodiado, sob cominação de multa;

IV - A petição inicial for instruída com prova documental suficiente dos fatos constitutivos do direito do autor, a que o réu não oponha prova capaz de gerar dúvida razoável.

Parágrafo único. Nas hipóteses dos incisos II e III, o juiz poderá decidir liminarmente. (BRASIL, 2015)

Destaca-se aqui o inciso IV do art. 311 do CPC, que determina que a tutela de evidência seja concedida quando ela for elaborada mediante provas documentais suficientes dos fatos constitutivos do direito do autor, ou seja, exige-se uma prova documental com potencialidade o suficiente para demonstrar o direito da parte, forte o bastante para que o réu não apresente, em sua contestação, uma prova que crie qualquer dúvida razoável. Assim, levando-se em consideração a grande possibilidade de veracidade das alegações do autor, a celeridade conferida pela tutela provisória de evidência, concede a parte, que comprova documentalmente o seu direito, em caráter liminar, a sua pretensão.

É importante mencionar que as tutelas provisórias, não possuem caráter definitivo, ou seja, não se equiparam a uma sentença, vez que quando essa medida provisória é concedida a uma parte, ela poderá sofrer modificações ou ser extinta a qualquer momento, conforme se demonstra por meio do art. 296 do CPC.

Art. 296. A tutela provisória conserva sua eficácia na pendência do processo, mas pode, a qualquer tempo, ser revogada ou modificada. (BRASIL, 2015)

No tangente a efetivação das tutelas provisórias, conforme dispõe o art. 297 do NCPC, entende-se que o juiz de direito poderá determinar as medidas cabíveis que entender que sejam adequadas para que haja a efetivação da tutela provisória, cumprindo o requerido pelas partes dentro dos próprios autos de maneira antecipada ou cautelar.

A demora na solução das demandas judiciais são uma das maiores injustiças ao qual é submetido o cidadão. Neste mesmo diapasão, Cappelletti (1988, p. 7), tece um breve comentário que coaduna com a ideia de que a demora que assola o judiciário é extremamente prejudicial para toda a sociedade: 
Em muitos países, as partes que buscam uma solução judicial precisam esperar dois ou três anos, por uma decisão exequível. Os efeitos dessa delonga, especialmente se considerados os índices de inflação, podem ser devastadores. Ela aumenta os custos para as partes e pressiona os economicamente fracos a abandonar suas causas, ou a aceitar acordos por valores muito inferiores àqueles a que teriam direito

Da mesma maneira, dentro sistema judiciário brasileiro visualiza-se a morosidade no tramite processual, afastando e postergando a resolução dos conflitos jurídicos, vez que processos podem permear por meses, anos ou até mesmo décadas. Com o advento do Código de Processo Civil de 2015, a regulamentação de algumas medidas de auto composição para resolução dos conflitos foram trazidas ao nosso ordenamento, visando desafogar o judiciário.

Contudo tais medidas não são suficientes para que haja a satisfação total das demandas, haja vista que nem todos os litígios conseguem ser solucionado por meio de tais medidas.

Assim o judiciário pode, por meio das tutelas provisórias, efetivar a prestação da tutela jurisdicional de forma mais célere, combatendo a morosidade da justiça, dando por intermédio das tutelas provisória, o alcance da ordem jurídica legítima e justa.

É imperioso lembrar que a própria Constituição Federal confere a todo cidadão o acesso à justiça, nos termos do inciso XXXV do Art. $5^{\circ}$ da $\mathrm{CF}$, fazendo com que as partes tenham um processo com duração razoável e célere, conforme demonstra-se pela leitura do inciso LXXVIII do art. $5^{\circ}$ da CF/88

Art. 5o, LXXVIII, da CF/88 - A todos, no âmbito judicial e administrativo, são assegurados a razoável duração do processo e os meios que garantam a celeridade de sua tramitação. (Incluído pela Emenda Constitucional $n^{\circ}$ 45, de 2004) (BRASIL, 1988)

A garantia de que o cidadão deve ter o direito à razoável duração do processo é um dos direcionamentos basilares do direito brasileiro. Neste mesmo sentido, o próprio Código de Processo Civil, em seu art. 4ํㅜㄹ reverbera os direcionamentos trazidos pela Constituição Cidadã de 1988, como demonstra-se no artigo 40 do CPC: "as partes têm o direito de obter em prazo razoável a solução integral do mérito, incluída a atividade satisfativa." (BRASIL, 2015).

Deste modo, as tutelas provisórias têm grande importância e, dentro do nosso ordenamento jurídico, exercem papel fundamental para a garantia da 
efetividade do processo judicial, combatendo diretamente a mora da justiça, cumprindo claramente o que exige e garante a Constituição Federal e o CPC no que tange à duração razoável do processo, concedendo, inclusive, a parte contrária o exercício do seu direito ao contraditório, haja vista que a decisão da tutela provisória não é definitiva, o que evita, além da morosidade do sistema judiciário, a procrastinação por parte dos réus que agem de má fé dentro do liame processual.

Assim, de um modo geral, as tutelas provisórias fazem com que a parte obtenha a tutela jurisdicional de forma antecipada, mitigando, inicialmente, alguns direitos processuais como o do contraditório, porém, visando atingir a celeridade processual, proporcionando a parte o acesso a ordem jurídica justa.

\section{Considerações finais}

O Código de Processo Civil trouxe uma das maiores contribuições para o combate à morosidade processual, a procrastinação das partes, garantindo a celeridade processual e a ordem jurídica, justa e eficaz, graças às tutelas provisórias, tanto as de urgência, quanto as tutelas de evidência, que trouxeram a possibilidade de conceder à sociedade a prestação de uma tutela jurisdicional efetiva e satisfatória.

Assim, as tutelas provisórias têm a capacidade de conferir às partes a prestação jurisdicional em tempo hábil e razoável, reduzindo as burocracias e formalidades excessivas dentro dos processos, efetivando a justiça, trazendo um grande avanço, evitando uma lesão dupla que ocorria antes da existência da presente legislação, onde o autor era inicialmente lesado pelo réu e, logo após, ainda teria que enfrentar todo um sistema moroso e burocrático processual, o que não deveria ocorrer agora, vez que o magistrado tem a capacidade de conceder à parte o seu direito, ainda que em caráter liminar, desde que atendido requisitos como a probabilidade do direito ou o risco de dano ao resultado útil do processo.

Por fim, reitera-se que as tutelas provisórias concedem às partes a garantia de seus direitos constitucionais como o acesso à ordem jurídica e a razoável duração do processo, o que agiliza a prestação da tutela jurisdicional graças a sumarização e simplificação do procedimento, o que contribui diretamente para a efetividade do processo. O judiciário tem que buscar sempre meios de atender a população, e combater a morosidade vivenciada no nosso ordenamento jurídico, as 
tutelas têm esse objetivo, mas outras providências devem ainda ser tomadas, para que os processos não ultrapassem a duração razoável e os direitos da população sejam garantidos.

\section{Referências}

ALVIM, Arruda. Novo Contencioso Cível no CPC/2015. São Paulo: Revista dos Tribunais; 2016

BRASIL. Constituição da República Federativa do Brasil de 1988. Casa Civil, Subchefia de Assuntos Jurídicos: Disponível em: <http://www.planalto.gov.br/ccivil_03/constituicao/constituicaocompilado.htm>; Acesso em 12 de fevereiro de 2018

BRASIL. Código de Processo Civil de 2015. Casa Civil, Subchefia de Assuntos Jurídicos: Disponível em: <http://www.planalto.gov.br/ccivil_03/_ato20152018/2015/lei//13105.htm>; Acesso em 12 de fevereiro de 2018

BUENO, Cássio Scapinella. Manual de Direito Processual Civil. 2ed. São Paulo: Saraiva, 2016.

CAPPELLETTI, Mauro; GARTH, Bryant: Acesso à Justiça. Traduzido por Ellen Gracie Northfleet. Porto Alegre: Fabris Editor, 1988.

NEVES, Daniel Amorim Assumpção. Manual de direito processual civil - Volume único,

8. ed. - Salvador: Ed. JusPodivm, 2016.

TALAMIN, Eduardo. Tutela provisória no novo CPC: panorama geral. 2016. Disponível em: <http://www.migalhas.com.br/dePeso/16,Ml236728,81042-

Tutela+provisoria+no+novo+CPC+panorama+geral> Acesso em 13 de fevereiro de 2018. 